\title{
Vertical-strain measurements in firn at Siple Dome, Antarctica
}

\author{
Robert L. HAWLEY, ${ }^{1}$ Edwin D. WADDINGTON, ${ }^{1}$ Gregg W. LAMOREY, ${ }^{2}$ \\ KENDRICK C. TAYLOR ${ }^{2}$ \\ ${ }^{1}$ Department of Earth and Space Sciences, Box 351650, University of Washington, Seattle, Washington 98195-1310, U.S.A. \\ E-mail:bo@u.washington.edu \\ ${ }^{2}$ Desert Research Institute, 2215 Raggio Parkway, Reno, Nevada 89512-1095, U.S.A.
}

\begin{abstract}
We measured vertical strain in the firn at Siple Dome, Antarctica, using two systems, both of which measure relative displacements over time of metal markers placed in an air-filled borehole. One system uses a metal-detecting tuned coil, and the other uses a video camera to locate the markers. We compare the merits of the two systems. We combine steady-state calculations and a measured density profile to estimate the true vertical-velocity profile. This allows us to calculate a depth-age scale for the firn at Siple Dome. Our steady-state depth-age scale has ages $\approx 10-15 \%$ younger at any given depth when compared to depth-age scales derived by layer counting in a core $40 \mathrm{~m}$ away. The age of a visible ash layer at $97 \mathrm{~m}$ in the core is $665 \pm 30$ years, in agreement with a similar analysis conducted at Taylor Dome, Antarctica, where the same ash is also seen, providing an additional dated tie point between the two cores.
\end{abstract}

\section{INTRODUCTION}

Measurements of vertical strain can add valuable information to a glaciological field program. Several methods of measuring vertical strain in firn and ice have been described (Hamilton and others, 1998; Zumberge and others, 2002; Elsberg and others, in press). However, most are primarily point measurements; detailed measurements of vertical strain in the firn are rarely made. Such measurements can provide insight into the mechanics of firn compaction by constraining the actual rates of compaction, and can be used to assign a depth-age relationship to the shallow sections of an ice core. This depth-age relationship, when combined with independent depth-age scales from other methods, can shed light on the possibility of transient variations in accumulation and surface density.

Siple Dome is an ice dome on the Siple Coast of West Antarctica $\left(81.65^{\circ} \mathrm{S}, 148.81^{\circ} \mathrm{W}\right)$. It is an "inter-ice-stream ridge"; the dome is a flow divide situated in slow-moving ice between Kamb and Bindschadler Ice Streams (former Ice Streams C and D). In the austral summers of 1997-99, an ice core was drilled $1004 \mathrm{~m}$ to bedrock. In addition to the main core, several smaller shallow cores were drilled. We made our vertical-strain measurements in an auxiliary borehole, $105 \mathrm{~m}$ deep and located $40 \mathrm{~m}$ from the main core site.

\section{MEASUREMENTS}

We made vertical-strain measurements using two different methods. We placed metal bands in the borehole at roughly $5 \mathrm{~m}$ intervals, and surveyed the locations of the bands over the course of three annual field seasons. We determined the location of a band both with a "metal-detector" tuned resonating inductive coil, and with a downward-looking borehole video camera. The tuned coil and the video camera provide different means of measuring the relative displacement of a band.

\section{Marking bands}

Each metal marking band is a strip of bronze spring stock, $10 \mathrm{~cm}$ wide and $1 \mathrm{~m}$ long (Rogers and LaChapelle, 1974; Raymond and others, 1994; Hawley and others, 2002). The strip is coiled on a custom injector tool and lowered into the borehole. When the band is released, it expands to press against the sides of the borehole. The logging tools can then pass through the coiled band to observe other bands at greater depths. In practice, the injection of the bands is time-consuming and difficult. At Siple Dome, the band at $84 \mathrm{~m}$ was snagged during the first logging run. Although we were able to free our logging tool, we did not attempt to re-log this band or the others below it until the final season of the project.

\section{Tuned coil}

The tuned-coil detector was built to a modification of the design presented in Rogers and LaChapelle (1974), based on the suggestions of Raymond and others (1994). It is essentially a metal detector, in which a circuit drives a signal through a coil, which is designed to produce resonance in the absence of nearby conductors. As the coil is brought close to a conductive object (in our case a metal band), current is induced in that object, and the resulting mutual inductance "detunes" the detector. This results in reduced resonance. The theory of the instrument is documented by Rogers and LaChapelle (1974) and Raymond and others (1994). In practice, our tool is slightly "detuned", so that resonance first increases when approaching a marker, and then 


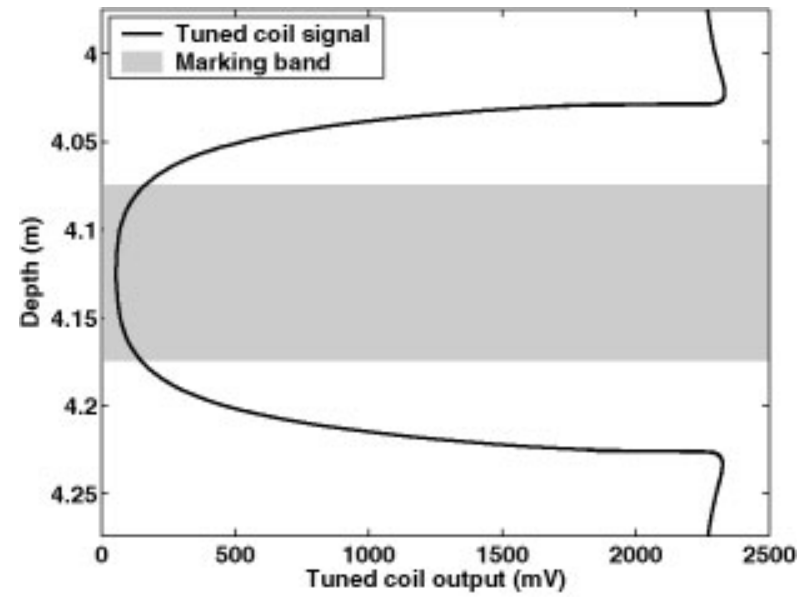

Fig. 1. Voltage output from the tuned-coil detector as it is lowered through a typical metal marking band (marked by the shaded area). Because the coil is not optimally tuned in free space, the resonance first increases when approaching the band, then decreases to a minimum when the tool is centered inside the band.

decreases as the tool enters the band. This provides more structure in the record for correlation. We suspended the instrument on a commercially available steel measuring tape with two conductors embedded in its edges to carry the signal. The voltage signal from the tool was recorded with a data logger. Upon reaching a band, we clamped a linear displacement transducer to the tape. The transducer allows very fine-scale measurement of depth over the short range spanning a marking band. In combination with the readings from the tape where the transducer was clamped, the result is a very accurate depth measurement. The transducer output was also recorded by the data logger. On the resulting voltage vs depth record (Fig. 1), the signal from the band is very distinct.

\section{Video}

We also located the bands with a downward-looking borehole video camera, using the technique described by Hawley and others (2002). For the first log, we made a permanent mark on the cable when we could image each band. We measured the distance between this mark and the top of the borehole casing with a vernier caliper for this and all subsequent images of this particular band edge.

The image of a band in the hole shows the edge of the band as a circle. We determine the location of the camera relative to the band by measuring the observed apparent radius of the band at a given camera position. The distance $d$ between the camera lens and the edge of the band can be expressed in terms of the focal length $f$ of the lens, the actual radius of the band $r_{\mathrm{a}}$, and the observed radius of the band $r_{\mathrm{o}}$ :

$$
d=\frac{f r_{\mathrm{a}}}{r_{\mathrm{o}}}
$$

Ideally we would select an optimum distance from each band to position the camera for caliper measurements, calculate the desired apparent radius $r_{\mathrm{d}}$ for that distance, and make the caliper measurement when the camera is positioned so that $r_{\mathrm{o}}=r_{\mathrm{d}}$. Since we did not have fine adjustment ability to position our tool, and had no accurate means of assessing the apparent radius in the field, we used the following "bracketing" approach to ensure we had positioned the camera in the same way from year to year.

For each band, we repeated the measurement at least three times, moving the camera vertically by approximately $1 \mathrm{~cm}$ each time. The resulting dataset consists of several images of the top and bottom edges of each band, each image taken from a different height above the band. Acquiring multiple images ensured that we could interpolate the measurement to the same distance $d$ relative to the band for each year. Although rearranging and integrating Equation (1) shows that observed apparent radius varies with the inverse square of the distance $d$, over a short range of $d$ $(\approx 3 \mathrm{~cm}$ in our case $)$ the relationship is almost linear.

\section{Density}

Density measurements were made on the "SDM-B" core, taken $40 \mathrm{~m}$ from the vertical-strain site. The density was determined by field measurements of the mass, length and diameter of ice-core sections approximately $1 \mathrm{~m}$ long. Two length measurements were made to the nearest millimeter using a metal ruler, and then averaged. In the case of angled breaks between sections, a minimum and a maximum length were measured and then averaged. The diameter was measured to the nearest $0.1 \mathrm{~mm}$ using digital calipers at three locations along the core section and these were also averaged. The mass was measured to the nearest gram using a triple-beam balance.

\section{DATA REDUCTION}

\section{Tuned coil}

The output from the tuned coil is saved in the form of a depth-voltage series for each band. To locate the midpoint of each band, previous users of this method (Rogers and LaChapelle, 1974; Raymond and others, 1994) chose a point midway between two "threshold" points of equal voltage on the sharply rising or falling voltage curve. In our analysis, we use the entire record. To compare two records of a given band from different years, we first normalize each curve to eliminate any effect of different temperatures or battery voltage on the amplitude of the signal. Then we crosscorrelate the two records. The offset producing the best cross-correlation is accepted as the relative displacement during the time interval between the records.

The band at $84 \mathrm{~m}$ was dislodged so as to partially block the borehole in the first season before we used the tuned-coil tool. Because the tuned-coil tool is large, we were unable to make tuned-coil measurements below $79 \mathrm{~m}$ depth.

\section{Video}

To find the radius of the band edge on each video image, we used an edge detection process to enhance the edge of the band. After extraneous edges were removed, the apparent radius of the band was determined by fitting a circle to the bright pixels of the band edge, using a least-squares process. For each band, we plotted the apparent radius of the band against the height of the permanent mark on the cable above the top of the borehole casing. The result was an almost linear relationship. Repeating the process the following year gave a similar line at a different height. The offset between 


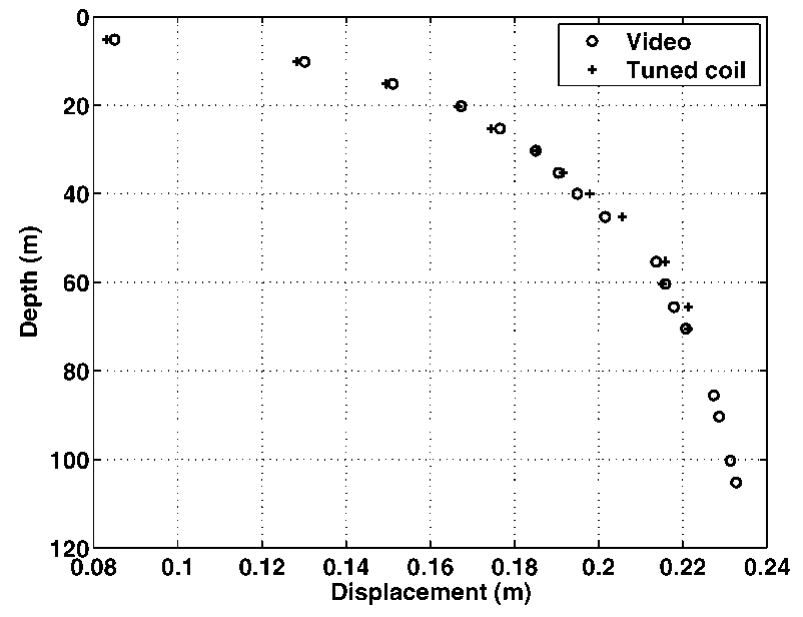

Fig. 2. Annual vertical displacements averaged over 2 years measured with both the video and tuned-coil tools. All motion is referenced to zero at the top of the borehole casing. The noticeable break in slope around $60 \mathrm{~m}$ is due to the change in densification rate at that depth.

the two lines gives the displacement of the band relative to our reference mark (i.e. the top of the casing).

We improved the band-edge detection algorithm; in the previous method we applied a numerical edge-detection filter and then manually removed extraneous edges in the image (such as parts of the camera that were in the field of view) before fitting a circle to the remaining bright pixels. The present method masks out the extraneous edges, and then fits a circle in several iterations, each time removing edge-detected pixels several standard deviations away from the best-fit circle. This removes reliance on the operator to find and remove all "noise" pixels. We believe that this improved the accuracy of the results at greater depths where reduced image contrast was previously a limitation.

\section{Density}

The largest source of uncertainty in the density measurements is missing pieces of unknown mass and volume due to breaks in the ice core. These sections of core were omitted from the density dataset. Another source of uncertainty is the length measurement where there was an angled break between adjacent sections. The average density for these adjacent sections often provided a reasonable density value. However, if the average density of a core section containing an angled break produced a suspect value, it was omitted from the density dataset. Densities have been interpolated for the ice-core sections with omitted values. The standard deviation of the density measurements is estimated to be $0.005 \mathrm{gm} \mathrm{cm}^{-3}$. Below $70 \mathrm{~m}$, the data show more noise; we expect this to be associated with missing pieces of core, resulting in low values.

\section{VERTICAL VELOCITY}

Our data analysis produces depth profiles of relative velocity, and of density, shown in Figures 2 and 3. Because we did not have data from the tuned-coil detector below $75 \mathrm{~m}$, we use the video data for vertical velocity and depthage scale analyses. We measured displacements, and hence velocity, relative to the borehole casing, which was attached to a plywood board at the surface and extended $\approx 1 \mathrm{~m}$ into

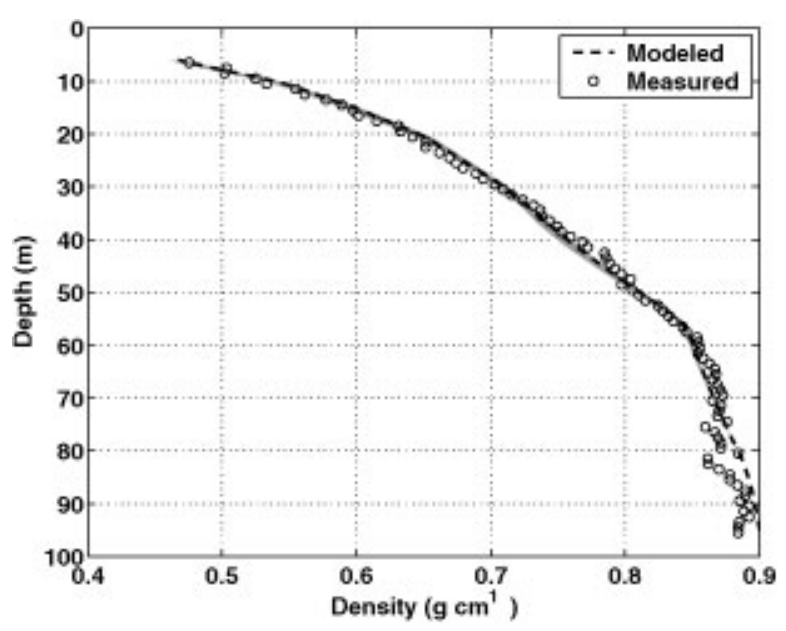

Fig. 3. Density data (circles) from the Siple Dome "B" core and our preferred "best-fit" modeled density profile (solid curve) using $\dot{b}=0.126 \mathrm{ma}^{-1}$. The shaded region contains all modeled density profiles that match the data better than our mismatch threshold of $J=1$. These solutions correspond to a range of $0.12-0.133 \mathrm{~m} \mathrm{a}^{-1}$ (ice equivalent) for $\dot{b}$. The narrowness of this region illustrates the relative insensitivity of our steady-state mass conservation model to differences of $<10 \%$ in accumulation rate.

the borehole. To convert to absolute velocity for use in calculating a depth-age scale, we follow the procedure of Hawley and others (2002). We start with our relative velocity, add an estimate of the true velocity of one point in the borehole, use conservation of mass to calculate a density profile with that velocity, and compare that to our measured density profile. We accept vertical velocity estimates that result in a close match between measured and modeled densities.

For our calculations, we introduce three assumptions: (1) The horizontal components $u(x)$ and $v(y)$ of the total velocity vector $\vec{V}(x, y, z)$, and therefore the horizontal strain rates, are independent of depth $z$ over the depth range of the survey. (2) The density $\rho(z)$ at a given depth is independent of horizontal position $x$ and $y$. (3) The density profile in the borehole is in steady state (Paterson, 1994, p. 14) such that

$$
\nabla \cdot(\rho \vec{V})=0 .
$$

The first assumption is valid for the shallow depths that we are concerned with here, where the largest motions are associated with firn densification. From horizontal strain measurements at the surface (Nereson, 1998) we know the total horizontal strain rate, which we indicate here as $\partial u / \partial x+\partial v / \partial y$.

For any given marker, the true vertical velocity is found by adding its measured velocity $w_{\mathrm{r}}(z)$ relative to the surface marker to the absolute downward velocity $w_{\mathrm{o}}$ of the surface marker.

Conservation of mass (Equation (2)) in a vertical column of ice from the surface to a depth $z^{\prime}$ in the borehole (here $100 \mathrm{~m}$ ) gives

$$
w_{\mathrm{o}} \rho_{\mathrm{o}}-w\left(z^{\prime}\right) \rho\left(z^{\prime}\right)=\left(\frac{\partial u}{\partial x}+\frac{\partial v}{\partial y}\right) \int_{0}^{z^{\prime}} \rho(z) \mathrm{d} z,
$$

where $\rho_{\mathrm{o}}$ is the density of snow at the top of the borehole.

Now, to express $w_{\mathrm{o}}$ entirely in terms of readily measurable quantities, we first recognize that $w_{\mathrm{o}}=w\left(z^{\prime}\right)-w_{\mathrm{r}}\left(z^{\prime}\right)$, 


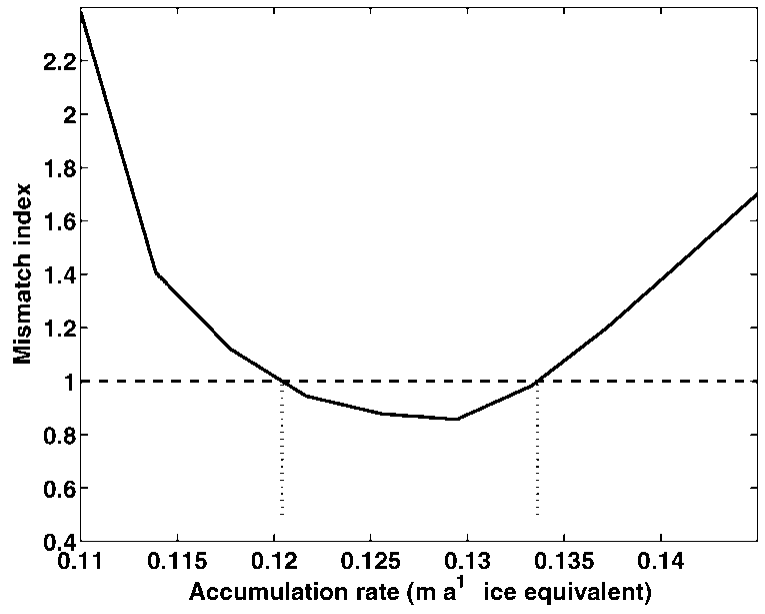

Fig. 4. Mismatch index J (Equation (6)) vs $\dot{b}$ for our density model. Our preferred "best fit" model uses $\dot{b}$ at the minimum $J$. We accept any result with a mismatch index $J>1$.

where we have already measured the relative velocity $w_{\mathrm{r}}\left(z^{\prime}\right)$ at the bottom of the borehole. Second, we note that the mass flux $w_{\mathrm{o}} \rho_{\mathrm{o}}$ through the upper surface of the ice sheet can also be written as $\dot{b} \rho_{\text {ice}}$, where $\dot{b}$ is ice equivalent accumulation rate, and $\rho_{\text {ice }}$ is the density of ice.

Third, we assume that the density $\rho\left(z^{\prime}\right)$ at the bottom of the borehole has reached the ice density $\rho_{\text {ice }}$ Incorporating this information into Equation (3) leads to

$$
w_{\mathrm{o}}=\dot{b}-\frac{1}{\rho\left(z^{\prime}\right)}\left(\frac{\partial u}{\partial x}+\frac{\partial v}{\partial y}\right) \int_{0}^{z^{\prime}} \rho(z) \mathrm{d} z-w_{\mathrm{r}}\left(z^{\prime}\right) .
$$

We then use $\dot{b}$ as the free parameter in the density model described below. In practice, the measured density at the bottom of our borehole did not reach the density of bubblefree ice, and so an additional factor of $\rho_{\text {ice }} / \rho\left(z^{\prime}\right)$ is included in the calculation of $w_{\mathrm{o}}$ to account for this.

Since the firn is compressible, vertical velocity is coupled to firn compaction. We find $w_{\mathrm{o}}$ by selecting the $\dot{b}$ that, when combined with our measurements and used in the calculations below, simultaneously produces a pair of coupled solutions $w(z)$ and $\rho(z)$ such that $\rho(z)$ best matches measured densities. We then accept that corresponding velocity solution $w(z)$.

Expanding Equation (2) with the assumptions above and then solving for $\partial \rho / \partial z$ yields

$$
\frac{\partial \rho}{\partial z}=-\left(\frac{\partial u}{\partial x}+\frac{\partial v}{\partial y}+\frac{\partial w}{\partial z}\right) \frac{\rho(z)}{w(z)}
$$

which can be integrated numerically to obtain a density profile, using measured values of $(\partial u / \partial x+\partial v / \partial y)$ and $\partial w / \partial z$. We computed density distributions using a range of possible values for $\dot{b}$ in Equation (4) when computing $w(z)$. For each $\dot{b}$, we compared the modeled density profile to measured density data. Our preferred profile is the one that matches the measurements most closely in a least-squares sense. This preferred profile is shown along with the measured densities in Figure 3. For each modeled density profile, we calculated a mismatch index

$$
J=\sqrt{\frac{1}{N} \sum_{i=1}^{N}\left(\frac{\left(\rho_{i}^{\mathrm{d}}-\rho_{i}^{\mathrm{m}}\right)}{2 \sigma}\right)^{2}}
$$

where $\rho_{i}^{\mathrm{d}}$ and $\rho_{i}^{\mathrm{m}}$ are the density data and modeled density at the $i$ th depth, respectively, $N$ is the number of samples, and $\sigma$ is the standard deviation of the measurements (estimated earlier as $0.005 \mathrm{gm} \mathrm{cm}^{-3}$ ). $J$ tells us how closely we match the density data with our model. $J=1$ means that we have on average matched the data within 2 standard deviations. Figure 4 shows the relation between $\dot{b}$ and $J$. We accept models producing $J<1$.

\section{DEPTH-AGE SGALE}

We use the vertical-velocity profile to calculate a depth-age scale for the upper $100 \mathrm{~m}$, following the procedure used by Paterson and others (1977) for Devon Ice Cap, Canadian Arctic, and by Hawley and others (2002) for Taylor Dome, Antarctica. We assume that the vertical velocity profile in the firn is in steady state in a reference frame fixed to the surface, which could be moving up or down due to changes in the thickness of the underlying ice. Although the particle paths are not precisely vertical, the horizontal components of $\vec{V}(x, y, z)$ are small enough that the vertical component is unlikely to vary significantly over the range of $x$ or $y$ spanned by the particle paths, so the one-dimensional approximation is valid.

We numerically integrate the inverse of the vertical velocity from the surface to depth $z$ to find the age today of ice at depth $z$,

$$
\text { Age }=\int_{0}^{z} \frac{1}{w(\xi)} \mathrm{d} \xi
$$

Using our preferred $w(z)$ profile, the resulting depth-age profile is shown by the bold curve in Figure 5. The shaded region on either side of the bold curve represents age profiles produced with all $w_{\mathrm{o}}$ values allowed by accepting only density models giving $J<1$ (see Fig. 4). Also shown for comparison are depth-age profiles determined using two layer-counting methods. In one method (Pennsylvania State University (PSU)), annual horizons in a core from $40 \mathrm{~m}$ away were visually counted to determine age (personal communication from R. B. Alley, 2003). In the other method (Desert Research Institute (DRI)) (Taylor and others, 2004), a computer algorithm was used to interpret annual layers using electrical conductivity measurements made on the same core.

\section{DISGUSSION}

\section{Comparison of the two methods}

The tuned-coil and video methods locate a marker in the borehole in different ways, and the opportunity to use the techniques side-by-side allows us to make comparisons. There are several benefits to using the tuned coil. The procedure for locating a band in any given record is straightforward and gives a robust indication of the location of the band. The tool, however, must be custom-built and cannot perform other functions. It is bulkier than the video tool, partly because the distance between the tool and the band on the borehole wall needs to be small. This distance requirement also means that different tools are needed for logging boreholes of different diameters.

With the video tool, we can inspect the condition of the borehole and the markers in real time. We use an unmodified commercial pipe-inspection camera, mounted on a simple frame. Data reduction with the video method is not straightforward, resulting in many steps 
between the raw video $\log$ and the vertical-strain result (Hawley and others, 2002).

The measured displacements from the two techniques agreed well, generally within a few millimeters. Both techniques require similar amounts of field time for a log. The limiting factor with both measurement types is probably the metal marker bands. They are difficult and time-consuming to place and, most importantly, they can be dislodged and block the borehole.

While our two methods span the firn at Siple Dome, there have been deeper vertical strain measurements made with optical fibers and wire strain meters. There is a small overlap between our shallow measurements and the deep measurements. Our shallow measurements agree closely with the deep measurements of both total vertical strain over the upper $80 \mathrm{~m}$ (Zumberge and others, 2002), and strain at $80 \mathrm{~m}$ depth on the $\approx 1 \mathrm{~m}$ scale of the wire strain meters (Elsberg and others, in press), improving confidence in both systems of measurement.

\section{Steady-state assumption}

Our estimated ages are consistently younger than those from annual-layer counts in the nearby ice core. One reason may be that our calculation assumes steady-state accumulation, with $\mathrm{a} \approx 700$ year average of $0.126 \mathrm{~m} \mathrm{a}^{-1}$. In Figure 5 we also show for comparison the depth-age profile generated using a $\dot{b}$ of $0.132 \mathrm{~m} \mathrm{a}^{-1}$, the 42 year average accumulation from Hamilton (2002). A profile generated using the minimum $\dot{b}$ suggested by the $1-\sigma$ uncertainty of $0.014 \mathrm{~m} \mathrm{a}^{-1}$ quoted by Hamilton (2002) lies between our region of $J<1$ and the PSU layer-counted age, while a profile generated using the maximum $\dot{b}$ suggested by the uncertainty is substantially younger than our preferred profile. Solving Equation (7) with a velocity profile generated using a $\dot{b}$ that is $10-15 \%$ lower than our preferred value brings the depth-age profile closely in line with the layer-counted ages. However, when we use a $10-15 \%$ lower $\dot{b}$ in our density model, the modeled densities do not fit as well with the measured densities. This inconsistency may indicate that Siple Dome is in fact not in steady state, but rather has had some non-steady accumulation or surface density history which we cannot identify in this steady-state analysis. Furthermore, our approach in which we match the modern density profile may be insensitive to such transients. There are spatial gradients in accumulation at Siple Dome (Nereson, 1998; Hamilton 2002), but they are small enough over a $40 \mathrm{~m}$ interval $(\approx 0.2 \%$, linearly interpolated $)$ that spatial accumulation patterns cannot explain the discrepancy. Further study into detection of transients in accumulation or surface density using firn densification models (e.g. Spencer and others, 2001) could shed more light on the accumulation-rate and surface density history of Siple Dome through the last millennium.

\section{Ash layer}

An ash layer is visible in the Siple Dome core at $\approx 97.5 \mathrm{~m}$ (Dunbar and others, 2002). This ash has been geochemically correlated with an ash layer at Taylor Dome (Dunbar and others, 2002; Hawley and others, 2002). At Taylor Dome, Hawley and others (2002) dated the ash layer at $675 \pm 25$ years using vertical-strain measurements and analysis similar to that presented in this paper. Our current analysis for Siple Dome dates the same ash layer at

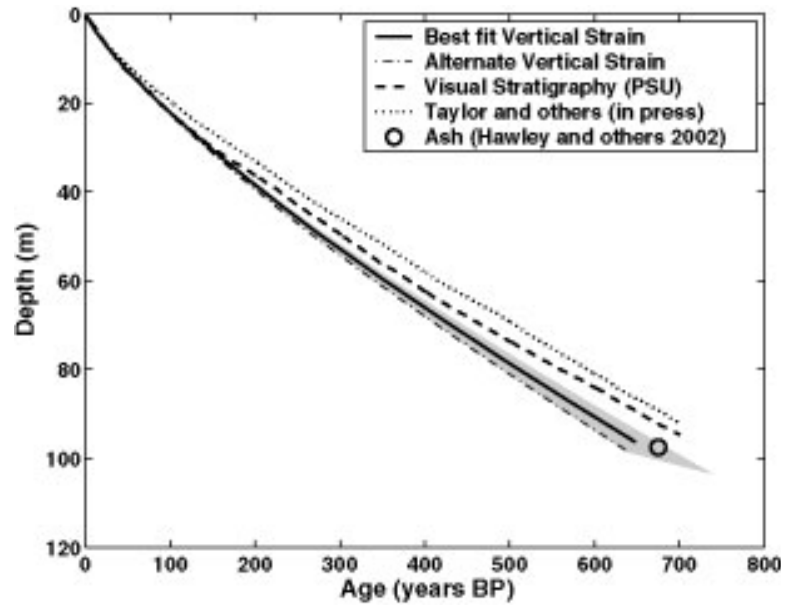

Fig. 5. Depth-age scale for the firn at Siple Dome. The solid curve uses our preferred accumulation of $0.126 \mathrm{ma}^{-1}$. The shaded region represents the range of possible depth-age scales with biving $J<1$. The dash-dot curve uses accumulation of $0.132 \mathrm{~m} \mathrm{a}^{-1}$ from Hamilton (2002). A volcanic ash layer at $97.5 \mathrm{~m}$ was also seen at Taylor Dome (Dunbar and others, 2002). It age of 675 years as dated at Taylor Dome by Hawley and others (2002) is indicated by the circle. Also shown are two independent depth-age scales for a nearby ice core, determined by counting visible annual layers (data from PSU: personal communication from R. B. Alley, 2003), and by counting annual stratigraphy in electrical conductivity records (data from DRI: Taylor and others, 2004). Our depth-age profile is younger on average, but within 10-15\% of the others.

$665 \pm 30$ years. The agreement between Taylor Dome and Siple Dome shows that our compaction analysis is self-consistent between these two different glaciological regimes.

\section{GONCLUSIONS}

We have evaluated two different methods for measuring vertical strain in the firn. Both have strengths and weaknesses. An important limitation to both methods appears to be the metal marker bands that are tracked over time, which are difficult to install and might be moved by the measuring tool. A future direction for vertical-strain measurement should be to track natural features in the borehole wall instead of artificial markers.

A density profile derived from our vertical-strain measurement matches well with measured values, under a range of acceptable accumulation rates. Our derived depth-age relationship is consistently $10-15 \%$ younger than depth-age scales derived from layer counting. Changing our long-term average accumulation rate by approximately $10-15 \%$ would bring the depth-age profile in line with those of other investigators, but our corresponding density profile then fails to match measured values. This contradiction may point to the possibility of transient behavior at Siple Dome on the $\approx 700$ year time-scale represented by the upper $100 \mathrm{~m}$.

\section{ACKNOWLEDGEMENTS}

We are grateful to G. Clow and R. Tremblay for assistance with field measurements. We thank J. Rogers and his engineering class at the California Maritime Academy, 
who designed and built our "tuned coil" detector. We thank all the Siple Dome layer counters (R. Alley, D. Meese, M. Spencer and S. Das) for the depth-age scales derived from their work. We thank K. Cuffey (Scientific Editor), R. Alley and G. Hamilton for insightful reviews that improved the manuscript. We thank E. Pettit for her helpful comments. This work was supported by U.S. National Science Foundation grants OPP-9726078 and OPP-9526420. Raytheon Polar Services and Antarctic Support Associates provided logistical support. The boreholes were drilled by the Polar Ice Coring Office.

\section{REFERENCES}

Dunbar, N., G. Zielinski and D. Voisins. 2002. Tephra layers in the Siple Dome and Taylor Dome ice cores, Antarctica: correlations and sources. 7. Geophys. Res., 108(B8). (10.1029/2002JB002056.)

Elsberg, D. H. and 6 others. In press. Depth- and time-dependent vertical strain rates at Siple Dome, Antarctica. F. Glaciol.

Hamilton, G. S. 2002. Mass balance and accumulation rate across Siple Dome, West Antarctica. Ann. Glaciol., 35, 102-106.
Hamilton, G. S., I. M. Whillans and P. J. Morgan. 1998. First point measurements of ice-sheet thickness change in Antarctica. Ann. Glaciol., 27, $125-129$.

Hawley, R. L., E. D. Waddington, D. L. Morse, N.W. Dunbar and G. A. Zielinski. 2002. Dating firn cores by vertical strain measurements. F. Glaciol., 48(162), 401-406.

Nereson, N. A. 1998. The flow history of Siple Dome and Ice Streams C and D, West Antarctica: inferences from geophysical measurements and ice flow models. (Ph.D. thesis, University of Washington.)

Paterson, W. S. B. 1994. The physics of glaciers. Third edition. Oxford, etc., Elsevier. Paterson, W. S. B. and 7 others. 1977. An oxygen-isotope climatic record from the Devon Island ice cap, Arctic Canada. Nature, 266(5602), 508-511.

Raymond, C. F., J. C. Rogers, P. L. Taylor and B. Koci. 1994. Vertical strain measurement in core holes. Nat. Inst. Polar Res. Mem., Ser. Special Issue 49, 234-240.

Rogers, J. C. and E. R. LaChapelle. 1974. The measurement of vertical strain in glacier bore holes. f. Glaciol., 13(68), 315-319.

Spencer, M. K., R. B. Alley and T. T. Creyts. 2001. Preliminary firn-densification model with 38-site dataset. f. Glaciol., 47(159), 671-676.

Taylor, K. C. and 13 others. 2004. Dating the Siple Dome (Antarctica) ice core by manual and computer interpretation of annual layering. 7. Glaciol., 50(170), 453-461.

Zumberge, M. A. and 6 others. 2002. Measurement of vertical strain and velocity at Siple Dome, Antarctica, with optical sensors. F. Glaciol., $48(161), 217-225$. 